\title{
The impact of an educational program on recognition, treatment and report of child abuse
}

\author{
Pietro Ferrara ${ }^{1,2^{*}}$ (D), Antonio Gatto ${ }^{1}$, Nunzia Pia Manganellii, Francesca lanniello ${ }^{1}$, Maria Elisa Amodeo ${ }^{2}$,
} Maria Amato $^{2}$, Ida Giardino ${ }^{3}$ and Antonio Chiaretti ${ }^{1}$

\begin{abstract}
Background: Pediatricians play a crucial role in the identification and management of child abuse and neglect (CAN) but they often don't have a formal specialized training.

Methods: We analysed retrospectively data about patients, 0 - 18 years of age, victims of CAN between 1 April 2005 and 30 April 2015. The aim of the study was to evaluate the effect of a multidisciplinary educational program, "CAN: prevention strategies, individuation and treatment", on the knowledge, case recognition, treatment and follow-up of physicians of Gemelli University Hospital in Rome, regarding physical, sexual abuse and neglect. This program, in 3 different editions biannually, respectively in May-July 2010, November-January 2012 and February-May 2014, was based on 4 sessions, each one of 2 days.

Results: Considering the number of victims of CAN between 2005 and 2015 we observed 66 cases of maltreatment. We divided the study population in 2 groups: group A, before the educational programs, patients evaluated from 1 April 2005 to 30 July 2010; group B, after the educational program from 1 August 2010 to 30 April 2015. We observed 23 children in group A and 43 children in group B with an improvement of $87 \%$. Analyzing our data about sex, nationality, type of perpetrators, we found that: $37 / 66$ (56\%) of children were females compared to 29/66 (44\%) males; 41/66 (62\%) of children came from Italy compared to 25/66 (38\%) of foreign children; 52/66 (79\%) of the perpetrators of abuse were parents or family members compared to acquaintances 10/66 (15\%) and to strangers 4/66 (6\%).

Conclusions: Considering the prevalence of CAN, the need to develop clinically competent clinicians and the improving of residency education in child maltreatment is imperative. Improving the clinical skills of pediatricians to identify and evaluate CAN may lead to reduce morbidity and mortality of these children.
\end{abstract}

Keywords: Child abuse, Maltreatment, Neglect, Training, Pediatricians

\section{Background}

Pediatricians play a crucial role in the identification and management of child abuse and neglect (CAN). They are the main investigator of recognizing and reporting suspected CAN. All physicians, in particular pediatricians, in CAN often are called on by courts as expert witnesses. Actually many physicians, however, have no formal specialized training in CAN. In 2008, a review of

\footnotetext{
* Correspondence: pietro.ferrara@unicatt.it

${ }^{1}$ Institute of Pediatrics, Catholic University Medical School, Rome, Italy

${ }^{2}$ Service of Pediatrics, Campus Bio-Medico University, Rome, Italy

Full list of author information is available at the end of the article
}

the professional education landscape found that no specific residency accreditation requirement exists for training in CAN [1].

Although there have been recent increases in recognition of CAN as a medical problem, there is no correlation of improved knowledge among physicians. Many pediatric residents leave residency with limited clinical training in CAN. After graduation, the programs of didactic training on CAN are described as very useful by physicians, but these didactic training are not mandatory so only a low number of physicians complete these elective activities.

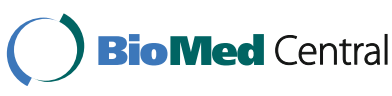

(c) The Author(s). 2017 Open Access This article is distributed under the terms of the Creative Commons Attribution 4.0 International License (http://creativecommons.org/licenses/by/4.0/), which permits unrestricted use, distribution, and reproduction in any medium, provided you give appropriate credit to the original author(s) and the source, provide a link to the Creative Commons license, and indicate if changes were made. The Creative Commons Public Domain Dedication waiver (http://creativecommons.org/publicdomain/zero/1.0/) applies to the data made available in this article, unless otherwise stated. 
Some authors demonstrated that the diagnosis of CAN is improved when physicians are adequately trained to recognize inflicted injuries and medical signs of abuse [2, 3]. Future research on training in CAN management and report is needed because there is very scarce and low-quality evidence on the accuracy of instruments for identifying abused children. Child maltreatment is mostly identified when children have already serious consequences and the sensitivities and specificities of tools are inadequate [4]. Before considering a screening program of child maltreatment, better knowledge on the beginning of child maltreatment and development of valid screening instruments at subclinical stages remain necessary [4].

\section{Methods}

We analysed retrospectively data about patients, 0 - 18 years of age, evaluated at Gemelli University Hospital in Rome, victims of CAN between 1 April 2005 and 30 April 2015.

The aim of the study was to evaluate the effect of a multidisciplinary educational program, "CAN: prevention strategies, individuation and treatment", on the knowledge, case recognition, treatment and follow-up of physicians of Gemelli University Hospital regarding physical, sexual abuse and neglect. This program, in 3 different editions biannually, respectively in May-July 2010, November-January 2012-2013 and February-May 2014, was based on 4 sessions, each one of 2 days. The 1st session based on a general overview of CAN, the 2nd on physical abuse, the 3rd on sexual abuse and 4th on neglect and legal considerations; each of the 4 sessions was designed to consider epidemiology, interviewing of victims, physical evaluation, behavioural, physical indicators and legal sequellae.

Using the centralized database of the Emergency Department (ED), accessed via GIPSE software, we identified the patients' number evaluated in ED and discharged with diagnosis of "child maltreatment or child sexual abuse".

To obtain the number of all patients who were both victims of CAN and hospitalized, but who were not diagnosed with CAN after the ED department evaluation, we analysed the archives of Gemelli Hospital Social Service. We consulted the medical record of each patient searching for data about age, sex, nationality, anamnesis, physical examination and diagnostic examinations.

In the absence of gold standard for ensuring identification of CAN, we condidered some proposed standards such us the number of evaluations at ED for each patient, after or before the hospitalization during the study period, expert assessments, substantiation by the child protection services or other social services, diagnosis by a medical, social or judicial team using one or several information sources (caregivers or child interview, child symptoms, child physical examination, and other medical record review).

We divided the study population in 2 groups: group A, before the educational programs, patients evaluated from 1 April 2005 to 30 July 2010; group B, after the educational program from 1 August 2010 to 30 April 2015.

We analysed data about categories of maltreatment (sexual abuse, physical abuse and neglect), age, gender, nationality. We also evaluated different type of aggressors, time of visits, injury severity and hospital admission. We highlighted also children victims of abuse with complex needs or difficult social conditions or with a risk patterns (living in foster care, drug-addicted-parents).

This is a retrospective study, designed to analyse preexisting data, collected from the medical records of patients, therefore there are some limitations such as selection bias and misclassification or information bias.

The study was carried out in compliance with the Helsinki Declaration and was approved by the Institute of Pediatrics of Catholic University, Rome.

\section{Results}

In ED 19 patients between 2005 and 2015 were evaluated with diagnosis of CAN. Four children (group A) received diagnosis between 1 April 2005 and 30 July 2010 (2 physical abuses, 2 sexual abuses); 15 (group B) between 1 August 2010 and 30 April 2015 (4 physical abuses, 11 sexual abuses) with an improvement of maltreatment diagnosis over $300 \%$. Sixty-three percent of patients (12/19) were female, 37\% (7/19) male; 32\% (6/19) were victims of physical abuse, $68 \%(13 / 19)$ were victims of sexual abuse (2 cases of oral sex, 2 of sexual penetration, 9 of sexual violence without penetration). The most common injury identified in these patients during the ED visit was ecchymosis with only one case of bite marks.

Evaluating the patients by age we observed that the mean age of patients victims of physical abuse was 6.0 years old and patients victims of sexual abuse was 11.6 years old. The perpetrators of abuse were parents or family members (13/19 - 68\%), acquaintances (out of family) (4/19 - 21\%) and stranger (2/19 - 11\%).

Considering nationality, 13 (68\%) children came from Italy compared to 6 (32\%) foreign children (usually from South East Europe). After the evaluation at ED, 23\% (3/ 13) sexually abused patients were discharged and $77 \%$ (10/13 patients) were hospitalized. Between the patients evaluated at ED 3/19 required a Neuropsychiatric treatment for the onset of panic attack, anxiety and sleep disorders.

Considering the time of admission to ED: 6/19 (32\%) patients were evaluated from 8.00 am to $02.00 \mathrm{pm}, 5 / 19$ (26\%) from $2.00 \mathrm{pm}$ to $08.00 \mathrm{pm}$ and $8 / 19$ (42\%) from $8.00 \mathrm{pm}$ to $02.00 \mathrm{am}$. 
Analysing the archives of Hospital Social Service, to estimate the number of all patients victims of CAN and hospitalized with a different diagnosis from child abuse after the evaluation in ED department, we found 47 cases. We identified this group of patients through the analysis of the medical record of each patient searching for data about anamnesis, physical examination and diagnostic examinations. Nineteen patients (group A), 28 patients (group B) with an increase of CAN diagnosis of about $50 \%$. The diagnosis were physical maltreatment for 21 (45\%) patients, (group A 10 cases, group B 11 cases), sexual abuse for 5 (10\%) patients (group A 1 case, group B 4 cases), neglect for 21 (45\%) patients, (group A 8 cases, group B 13 cases).

Evaluating the patients by sex and nationality we found that $53 \%(25 / 47)$ were females, $47 \%(22 / 47)$ males and $60 \%(28 / 47)$ came from Italy compared to $40 \%(19 / 47)$ foreign children. Clinical characteristics of physical maltreatment were summarized in Table 1. Fifteen children (32\%) required Neuropsychiatric treatment, in particular 2 cases due to suicide attempt and psychosis 1 case.

The perpetrators of abuse included parents or family members (39/47 - 83\%), acquaintances (out of family) (6/ $47-13 \%)$ and strangers $(2 / 47-4 \%)$.

Between the several categories of neglect we observed medical neglect in $43 \%$ of patients.

Considering the number of victims of CAN between 2005 and 2015 we observed 66 cases of maltreatment: 23 children in group A and 43 children in group B with an improvement of $87 \%$. Summarising our data about sex, nationality, type of perpetrators, we found that:

- $37 / 66$ (56\%) of children were females compared to 29/66 (44\%) males;

- 41/66 (62\%) of children came from Italy compared to $25 / 66$ (38\%) of foreign children;

- 52/66 (79\%) of the perpetrators of abuse were parents or family members compared to acquaintances 10/66 (15\%) and to strangers 4/66 (6\%).

Finally, considering children victims of abuse, with complex needs or difficult social conditions or with a risk patterns, we identified: 2 children lived in foster care, 3 with drug-addicted-parents and 1 with post traumatic stress disorder (Table 2).

Table 1 Clinical characteristics of physical maltreatment

\begin{tabular}{ll}
\hline Diagnosis & Cases \\
\hline Head injury & 7 \\
Skin lesions & 5 \\
Poisoning & 4 \\
Polytrauma & 3 \\
Others & 2 \\
\hline
\end{tabular}

\section{Discussion}

Our study demonstrated that training about CAN for pediatricians was associated with increased identification of victims of CAN.

The foundation of their competency in this role is established during their residency. Many authors have found areas of strength and weaknesses in current pediatric residency child abuse curricula $[5,6]$. In the USA the recent creation of a Child Abuse Pediatrician subspecialty represents an opportunity to establish national standardized recommendations for child abuse training curricula and to identify several factors, including the presence of a written curriculum, that contribute to increased confidence among residents.

According to our study, available research demonstrates that different training strategies can improve knowledge and preparedness related to the recognition and response of CAN.

Starling et al. compared the training and knowledge in the United States among the 3 specialties most likely to encounter abused children: pediatrics, emergency medicine, and family medicine. Analyzing the survey received from 53 program directors and 462 residents they found that pediatric programs provide far more training and resources for child abuse education than emergency medicine and family medicine programs [5].

Narayan et al. analyzed with a survey the preparedness of residents to address CAN on graduation [7]. A 28-item survey was sent to chief residents of all 203 Accreditation Council for Graduate Medical Education-accredited pediatric residency programs in the United States from 2004 to 2005 . The response rate was $71 \%$. Respondents rated the levels of preparedness of graduating residents to address CAN as: very well (12\%), well (54\%), somewhat well $(28 \%)$, or not well $(6 \%)$. They demonstrated that the preparedness was significantly associated with hours of didactics, number of inpatient cases of CAN seen, number of sexual and physical abuse cases during mandatory rotation, and length of mandatory rotation [7]. They compared also their data with a similar study, by Dubowitz et al. conducted in 1988, and noted that not be a large difference between the perceived adequacy of training of residents over the two decades despite the impact of this problem on social and public health.

Hibbard et al. described the effect of a multidisciplinary project carried out in Indiana to educate medical, child protective and legal professional in the evaluation and care of children victims of child abuse [8]. The program was designed to accomplish 5 tasks: behavioural and physical indicator, interview, the use of dolls and drawing as interviewing aids, medical evaluation and legal responsibilities. The program was conducted with didactic presentation and discussions. They demonstrated an improved knowledge score at 2 weeks post-program and at 6 months [8]. 
Table 2 Characteristics of patients

\begin{tabular}{|c|c|c|c|c|c|c|c|c|c|c|}
\hline & & \multicolumn{3}{|c|}{$\begin{array}{l}\text { Group A } \\
2005-2010\end{array}$} & \multicolumn{3}{|c|}{$\begin{array}{l}\text { Group B } \\
\text { 2010-2015 }\end{array}$} & \multicolumn{3}{|c|}{ Group B vs Group A } \\
\hline & & ED & Hospitalization & total & $\mathrm{ED}$ & Hospitalization & total & ED & Hospitalization & total \\
\hline \multicolumn{2}{|c|}{ Patients n (\%) } & $4(17.4)$ & $19(82.6)$ & 23 & $15(34.9)$ & $28(65.1)$ & 43 & $+11(55.0)$ & +9 (45.0) & +20 \\
\hline \multirow[t]{2}{*}{ Sex } & Male n (\%) & $1(11.1)$ & $8(89.9)$ & 9 & $6(30.0)$ & $14(70.0)$ & 20 & $+5(45.4)$ & $+6(56.4)$ & +11 \\
\hline & Female n (\%) & $3(21.4)$ & $11(78.6)$ & 14 & $9(39.1)$ & $14(60.9)$ & 23 & $+6(66.7)$ & $+3(32.3)$ & +9 \\
\hline \multirow[t]{2}{*}{ Nationality } & Italian children n (\%) & $3(20.0)$ & $12(80.0)$ & 15 & $10(38.5)$ & $16(61.5)$ & 26 & $+7(63.6)$ & $+4(36.4)$ & +11 \\
\hline & Foreign children n (\%) & $1(12.5)$ & $7(87.5)$ & 8 & $5(29.4)$ & $12(70.6)$ & 17 & $+4(44.4)$ & $+5(55.6)$ & +9 \\
\hline \multirow[t]{3}{*}{ Abuse } & Physical abuse n (\%) & $2(16.7)$ & $10(83.3)$ & 12 & $4(26.7)$ & $11(73.3)$ & 15 & $+2(66.7)$ & $+1(33.3)$ & +3 \\
\hline & Sexual abuse n (\%) & $2(66.7)$ & $1(33.3)$ & 3 & $11(73.3)$ & $4(26.7)$ & 15 & +9 (75.0) & $+3(25.0)$ & +12 \\
\hline & Neglect n (\%) & $0(0.0)$ & $8(100.0)$ & 8 & $0(0.0)$ & $13(100.0)$ & 13 & / & $+5(100.0)$ & +5 \\
\hline
\end{tabular}

In the literature, there is also a study by Showers et al. about the effect of self-instructional programs on physical and sexual abuse on emergency physicians [9]. The project was base on 2 self-instructional programs of about $6 \mathrm{~h}$ designed to study in the home or office. Topics in the didactic sections included incidence and consequences, legal aspects and documentation, risk and suspicion, types of abuse, interview techniques and treatment [9]. The project resulted in significant improvement in the knowledge.

These studies and experiences demonstrate that different tools can conduct to the same result and they are very useful to increase the best practice on this hot topic. In Italy actually there is no specific required training in CAN during graduation.

Our study suggests that the physicians should receive enough training to accurately identify and report abuse when it is suspected. Moreover, aside from identification, training can improve pediatricians' ability to safely and sensitively respond to children exposed to maltreatment and their families, including improved communication in initial encounters, increased support to children and families in connecting with community services [10,11]. First of all, is important to not underestimate symptoms such as abdominal pain and voiding disorders, in this cases it is fundamental to deal out organic causes for example taking drugs or rare diseases. So particularly, for abdominal pain and voiding disorders is important to rule out organic causes such as taking medication or other rare diseases [12].

Many programs should begin the process of implementing CAN training. In particular we believe that the CAN training not to be focused only on physical and sexual abuse but also on neglect or domestic violence. Neglect is the most common form of child abuse and the relationship between domestic violence and CAN has been well established [13-18].

Specific sessions on neglect and domestic violence training are mandatory in all didactic training programs on CAN.
There also is a need for a national CAN curriculum that can be adapted to any training site. Considering the incidence of CAN we think that the well-being of children depends on a well-trained and knowledgeable force of physicians who can identify and prevent CAN.

Characteristics of our sample may limit the generalization of the findings but our study is an example of efficacy of post-graduate training but to employ the medical practice on CAN, considering that child maltreatment is more prevalent than cancer and just as fatal, is necessary to have structured mandatory rotations for residencies. Furthermore the evolution of the concept of CAN leads to consider new types of maltreatment that in the future will certainly be taken into account with a new era of social paediatrics [19-21].

Domestic and interpersonal violence are public health problems so we think that it should warrant more attention during residency training on family violence as well as anatomy, molecular biology, genetic diseases or infective diseases.

\section{Conclusions}

Considering the prevalence of CAN, the need to develop clinically competent clinicians and the improving of residency education in child maltreatment is imperative. Improving the clinical skills of pediatricians to identify and evaluate CAN may lead to reduce morbidity and mortality of these children. Training in early identification of CAN may improve outcomes of these children.

\section{Abbreviations}

CAN: Child abuse and neglect; ED: Emergency Department

\section{Acknowledgments}

Not applicable.

Funding

The authors declare no funding for this work.

\section{Availability of data and materials}

The datasets used and/or analysed during the current study available from the corresponding author on reasonable request. 


\section{Authors' contributions}

All authors contributed in the same way to collect, analyze and interpret data and write the manuscript; all authors read and approved the final draft.

\section{Ethics approval and consent to participate}

The study was carried out in compliance with the Helsinki Declaration and was approved by the Institute of Pediatrics of Catholic University, Rome.

\section{Consent for publication}

Not applicable.

\section{Competing interests}

The authors declare that they have no competing interests.

\section{Publisher's Note}

Springer Nature remains neutral with regard to jurisdictional claims in published maps and institutional affiliations.

\section{Author details}

${ }^{1}$ Institute of Pediatrics, Catholic University Medical School, Rome, Italy. ${ }^{2}$ Service of Pediatrics, Campus Bio-Medico University, Rome, Italy. ${ }^{3}$ Department of Clinical and Experimental Medicine, University of Foggia, Foggia, Italy.

Received: 8 April 2017 Accepted: 3 August 2017

Published online: 14 August 2017

\section{References}

1. Christian CW. Professional education in child abuse and neglect. Pediatrics. 2008;122:513-7.

2. Jenny C, Hymel K, Ritzen A, Reinert SE, Hay TC. Analysis of missed cases of abusive head trauma. [published correction appears in JAMA. 1999;282(1): 29]. JAMA 1999;281:621-626.

3. Paradise JE, Winter MR, Finkel MA, Berenson AB, Beiser S. Influence of the history on physicians' interpretations of girls'genital findings. Pediatrics. 1999;103:980-6.

4. Bailhache $M$, Leroy $V$, Pillet $P$, Salmi LR. Is early detection of abused children possible?: a systematic review of the diagnostic accuracy of the identification of abused children. BMC Pediatr. 2013:13:202

5. Starling SP, Heisler KW, Paulson JF, Youmans E. Child abuse training and knowledge: a national survey of emergency medicine, family medicine, and pediatric residents and program directors. Pediatrics. 2009;123:595-602.

6. Dara JS, Kotlar EY, Leekoff ML, Tran XG, McColgan MD, Giardino AP. Resident comfort level after receiving child abuse training: a survey of pediatric chief residents. Child Abuse Negl. 2013;37:489-91.

7. Narayan AP, Socolar RR, St Claire K. Pediatric residency training in child abuse and neglect in the United States. Pediatrics. 2006;117:2215-21.

8. Hibbard RA, Serwint J, Connolly M. Educational program on evaluation of alleged sexual abuse victims. Child Abuse Negl. 1987;11:513-9.

9. Showers J, Laird M. Improving knowledge of emergency physicians about child physical and sexual abuse. Pediatr Emerg Care. 1991;7:275-7.

10. McTavish JR, MacGregor JC, Wathen CN, Mac Millan HL. Children's exposure to intimate partner violence: an overview. Int Rev Psychiatry. 2016;28(5):504-18.

11. Pettoello-Mantovani M, Campanozzi A, Maiuri L, Giardino I. Family oriented and family centered care in pediatrics. Ital J Pediatr. 2009;35(1):12.

12. Garcovich S, Gatto A, Ferrara P, Garcovich A. Vulvar pyoderma gangrenosum in a child. Ped Derm. 2009:26(5):629-31.

13. Wright RJ, Wright RO, Isaac NE. Response to battered mothers in the pediatric emergency department: a call for an interdisciplinary approach to family violence. Pediatrics. 1997;99:186-92.

14. Ferrara $P$, Vitelli $O$, Bottaro $G$, Gatto A, Liberatore $P$, Binetti $P$, Stabile A. Factitious disorders and Munchausen syndrome: the tip of the iceberg. J Child Health Care. 2013:17:366-74.

15. Ferrara P, Bernasconi S. From "classic" child abuse and neglect to the new era of maltreatment. Ital J Pediatr. 2017;43(1):16.

16. Ferrara P, Romani L, Bottaro G, lanniello F, Fabrizio GC, Chiaretti A, Alvaro F. The physical and mental health of children in foster care. Iran J Public Health. 2013:42(4):368-73.

17. Ferrara P, Corsello G, Sbordone A, Nigri L, Ehrich J, Pettoello-Mantovani M. Foster Care: a fragile reality needing social attention, and economic investments. J Pediatr. 2016;173:270-1.
18. Ferrara P, Vena F, Caporale O, Del Volgo V, Liberatore P, lanniello F, Chiaretti A, Riccardi R. Children left unattended in parked vehicles: a focus on recent italian cases and a review of literature. Ital J Pediatr. 2013;39:71.

19. Ferrara P, Corsello G, Sbordone A, Cutrona C, Ehrich J, Pettoello-Mantovani $M$. The role of pediatricians in caring for the well-being of children living in new types of families. J Pediatr. 2016;176:226-8.

20. Ferrara P, Corsello G, Basile MC, Nigri L, Campanozzi A, Ehrich J, PettoelloMantovani M. The economic burden of child maltreatment in high income countries. J Pediatr. 2015:167(6):1457-9.

21. Ferrara $P$, lanniello $F$, Cutrona $C$, et al. A focus on recent cases of suicides among Italian children and adolescents and a review of literature. Ital. J Pediatr. 2014;15:40. 69

\section{Submit your next manuscript to BioMed Central and we will help you at every step:}

- We accept pre-submission inquiries

- Our selector tool helps you to find the most relevant journal

- We provide round the clock customer support

- Convenient online submission

- Thorough peer review

- Inclusion in PubMed and all major indexing services

- Maximum visibility for your research

Submit your manuscript at www.biomedcentral.com/submit
Biomed Central 